\title{
Apolipoproteins, cardiovascular risk and statin response in type 2 diabetes: the Collaborative Atorvastatin Diabetes Study (CARDS)
}

\author{
V. Charlton-Menys $\cdot$ D. J. Betteridge $\cdot$ H. Colhoun $\cdot$ \\ J. Fuller • M. France • G. A. Hitman • S. J. Livingstone • \\ H. A. W. Neil • C. B. Newman • M. Szarek • \\ D. A. DeMicco • P. N. Durrington
}

Published online: 17 December 2008

(C) Springer-Verlag 2008

\section{Erratum to: Diabetologia}

DOI 10.1007/s00125-008-1176-8

The authors apologise for the following mistakes in this paper:

\section{Abstract}

The areas under the receiver operator curve for the ApoB:ApoA-I and the LDLC to HDLC ratios [corrected from 'LDLC to HDL-HDLC ratios'], although not significantly different from each other, were greater $(p=0.0005$ and $p=0.0125$ respectively) than that of non-HDLC:HDLC.

The online version of the original article can be found at http://dx.doi. org/10.1007/s00125-008-1176-8.

V. Charlton-Menys $\cdot$ P. N. Durrington $(\square)$

Cardiovascular Research Group,

School of Clinical \& Laboratory Sciences,

Core Technology Facility (3rd Floor),

University of Manchester,

46 Grafton Street,

Manchester M13 9NT, UK

e-mail: pdurrington@manchester.ac.uk

D. J. Betteridge

Department of Medicine, Jules Thorne Institute,

The Middlesex Hospital,

London, UK

H. Colhoun

Department of Public Health, University of Dundee,

Dundee, UK

J. Fuller $\cdot$ S. J. Livingstone

Department of Epidemiology \& Public Health,

University College London,

London, UK
Discussion, paragraph 2

However, by ROC analysis, although clearly better [corrected from 'although not clearly better'] than nonHDLC:HDLC, the ApoB:ApoA-I ratio did not significantly improve on LDLC:HDLC.

Discussion, penultimate paragraph

In epidemiological studies, stroke incidence is also less strongly associated [corrected from 'also strongly associated'] with lipoproteins that are associated with CHD [31, 32].

\section{France}

Department of Clinical Biochemistry,

Manchester Royal Infirmary,

Manchester, UK

\section{G. A. Hitman}

Centre for Diabetes and Metabolic Medicine,

Queen Mary's School of Medicine University of London,

London, UK

H. A. W. Neil

Division of Public Health \& Primary Health Care,

University of Oxford,

Oxford, UK

C. B. Newman

Department of Medicine,

New York University School of Medicine,

New York, USA

M. Szarek - D. A. DeMicco

Pfizer Global Medical,

New York, USA 